Article

\title{
Optimization of Sonotrode Ultrasonic-Assisted Extraction of Proanthocyanidins from Brewers' Spent Grains
}

\author{
Beatriz Martín-García ${ }^{1}$, Federica Pasini ${ }^{2}$, Vito Verardo ${ }^{3,4, * \mathbb{D}}$, Elixabet Díaz-de-Cerio ${ }^{3}$, \\ Urszula Tylewicz $^{2}{ }^{\circledR}$, Ana María Gómez-Caravaca ${ }^{1}$ and Maria Fiorenza Caboni ${ }^{2,5}$ \\ 1 Department of Analytical Chemistry, Faculty of Sciences, University of Granada, Avd. Fuentenueva s/n, \\ 18071 Granada, Spain \\ 2 Department of Agricultural and Food Sciences, University of Bologna, Piazza Goidanich 60, \\ (FC) 47521 Cesena, Italy \\ 3 Department of Nutrition and Food Science, University of Granada, Campus of Cartuja, 18071 Granada, Spain \\ 4 Institute of Nutrition and Food Technology 'José Mataix', Biomedical Research Center, \\ University of Granada, Avda del Conocimiento sn, 18100 Armilla, Granada, Spain \\ 5 Interdepartmental Centre for Agri-Food Industrial Research, Alma Mater Studiorum, Università di Bologna, \\ via Quinto Bucci 336, 47521 Cesena (FC), Italy \\ * Correspondence: vitoverardo@ugr.es; Tel.: +34-958243863
}

Received: 28 June 2019; Accepted: 31 July 2019; Published: 6 August 2019

check for updates

\begin{abstract}
Brewing spent grains (BSGs) are the main by-product from breweries and they are rich of proanthocyanidins, among other phenolic compounds. However, literature on these compounds in BSGs is scarce. Thus, this research focuses on the establishment of ultrasound-assisted extraction of proanthocyanidin compounds in brewing spent grains using a sonotrode. To set the sonotrode extraction up, response surface methodology (RSM) was used to study the effects of three factors, namely, solvent composition, time of extraction, and ultrasound power. Qualitative and quantitative analyses of proanthocyanidin compounds were performed using HPLC coupled to fluorometric and mass spectrometer detectors. The highest content of proanthocyanidins was obtained using 80/20 acetone/water $(v / v), 55 \mathrm{~min}$, and $400 \mathrm{~W}$. The established method allows the extraction of $1.01 \mathrm{mg} / \mathrm{g}$ dry weight (d.w.) of pronthocyanidins from BSGs; this value is more than two times higher than conventional extraction.
\end{abstract}

Keywords: Box-Behnken design; proanthocyanidins; Brewers' spent grains; sonotrode ultrasonic-assisted extraction; HPLC-fluorometric detector (FLD)-MS

\section{Introduction}

Barley is the basic raw material for brewing. Phenolic compounds identified in barley include flavonoids, phenolic acids, and proanthocyanidins (PCs) [1,2]. There are more than 50 PCs in barley, comprising flavan-3-ol oligomers and their polymers [3]. The oligomers include dimers (prodelphinidin B3 and procyanidin B3), trimers, tetramers, and pentamers, while polymers are formed by oxidation and polymerization of simple flavan-3-ols [4]. Barley PCs ranged from 25 to $250 \mathrm{mg} / 100 \mathrm{~g}$ of grain [5-8]. Among them, proanthocyanidin trimers, such as catechin-gallocatechin-catechin $(\mathrm{C}-\mathrm{GC}-\mathrm{C})$, prodelphinidin B3 and procyanidin B2 [9] are the most representative in barley. In addition, hops also contribute to the proanthocyanidin content in brewing spent grains (BSGs); in fact, according to several authors, this ingredient contains high amounts of catechin and procyanidins $[10,11]$.

Furthermore, PCs showed anti-bacterial [12], anti-viral [13], anti-carcinogenic [14], anti-inflammatory [15], and cardioprotective effects [16]. Some studies demonstrated the potential 
of PCs for prevention or treatment of oxidative stress-associated diseases due to their antioxidant capacity [17]. In addition, PCs are easily extracted, affordable, and demonstrated low toxicity [17].

During the process of brewing, many BSGs are generated from barley grains after separation of the wort, and they consist of the residues from malted barley which could contain adjuncts (non-malt sources of fermentable sugars) such as wheat, rice, or maize and hop added during mashing [1]. Consequently, this by-product is rich in protein, fibers, arabinoxylans, and $\beta$-glucan, and also contains PCs in low concentration; thus, its reutilization could be useful for the food industry, and offers an opportunity for cereal-based baked and extruded products with acceptable sensory and nutritional characteristics [1].

In this sense, the challenge is to increase the efficient collection of PC-rich extracts with high bioactivity by the optimization of the extraction process. Thus far, conventional solid/liquid extraction was often used, employing as an extraction solvent a mixture of acetone and water in proportions from $50 / 50$ to $80 / 20[4,8,18,19]$ due to the large number of $\mathrm{OH}$ groups in PCs. In addition, bath-ultrasound-assisted extraction is the most used extraction technique. Some authors carried out pressurized solvent extraction, which is a static solid/liquid extraction with high pressure and eventually high temperature in stainless-steel extraction cells. Nevertheless, conventional extractions using ultrasonic-assisted extraction seem to be the best choice, since it is an economical technique, can be performed at atmospheric pressure and ambient temperature, and it could be developed on an ultrasound (US) bath or even with an US probe (or sonotrode) [20,21].

To carry out the determination of PCs in cereal, high-performance liquid chromatography (HPLC) is the analytical technique usually applied to this aim. In many instances, this technique was coupled to a diode array detector (DAD), fluorometric detector (FLD), and mass spectrometer detector (MSD) [8,22,23], or matrix-assisted laser desorption/ionization time-of-flight (MALDI-TOF) analysis [24].

In view of the above, the objective of this work was to evaluate the recovery of proanthocyanidins from BSGs by establishing a sonotrode ultrasonic-assisted extraction method. For that purpose, response surface methodology (RSM) was performed to evaluate extraction parameters with an experimental Box-Behnken design.

\section{Materials and Methods}

\subsection{Samples}

Brewers' spent grain (BSG) samples were obtained in a micro-brewing plant after pilsner beer production (Mastrobirraio, Cesena, Italy, $44^{\circ} 08^{\prime} 00^{\prime \prime}$ north $(\mathrm{N}), 12^{\circ} 14^{\prime} 00^{\prime \prime}$ east $€$ ).

\subsection{Chemicals}

HPLC-grade water and solvents were purchased from Merck KGaA (Darmstadt, Germany). Catechin was purchased from Sigma-Aldrich (St. Louis, MO).

\subsection{Experimental Design}

Response surface methodology (RSM) is the most popular tool for modeling. In RSM, statistical models and polynomial equations are always combined to provide an approximate relationship between the dependent and independent variables [25]. In the present work, a Box-Behnken design (BBD) with three factors was carried out in order to optimize the extraction parameters of proanthocyanidins in BSGs. The parameters of ultrasound-assisted extraction (US) can be divided into US parameters (ultrasound frequency, duration, acoustic power/intensity, and treatment mode) and non-US parameters (solvent type, solvent/sample ratio, particle size, temperature) [25]. In this work, the factors investigated were acetone/water $(X 1)$, time $(X 2)$, and potency $(X 3)$, with three levels for each factor, and the response variable $(\mathrm{Y})$ was the sum of the total content of proanthocyanidins (PCs). The range for the percentage of acetone/water was chosen based on the conditions previously established in other works $(50,75$, and 
$100 \%)[4,8]$; the extraction time $(5,30$, and $55 \mathrm{~min})$ and the US power $(80,240$, and $400 \mathrm{~W})$ were the same as those previously used in a study where a sonotrode US was employed to optimize these parameters for the extraction of phenolic compounds from Psidium guajava L. leaves [26]. The design consisted of 15 combinations including three center points (Table 1), and the experiments were randomized to maximize the effects of unexplained variability in the observed response, due to extraneous factors.

The determination of optimal US sonotrode parameters was carried out using STATISTICA 7.0 (2002, StatSoft, Tulsa, OK).

\subsection{Extraction of Proanthocyanidins from Brewers' Spent Grains by Sonotrode Ultrasonic Extraction}

The extraction was achieved with a US sonotrode UP400St (Hielscher Ultrasonics GmbH, Teltow, Germany) and, during the extraction, an ice bath was used to avoid rises in temperature. The temperature ranged between 23 and $25{ }^{\circ} \mathrm{C}$ in all extractions, and it was measured with a thermometer at the end of each extraction. The percentage of acetone/water, the extraction time, and the US power were varied according to the experimental design. After the extraction, samples were centrifuged at $1000 \times \mathrm{g}$ for $10 \mathrm{~min}$; supernatants were collected, evaporated, and reconstituted in $1 \mathrm{~mL}$ of methanol/water $(1 / 1, v / v)$. The final extracts were filtered through $0.2-\mu \mathrm{m}$ polytetrafluoroethylene (PTFE) syringe filters and stored at $-18^{\circ} \mathrm{C}$ until the analyses.

\subsection{Conventional Extraction of Proanthocyanidins}

The results obtained by the US sonotrode at the optimal conditions were compared with a PC extract from BSGs obtained via conventional solid/liquid extraction. The extraction methodology was carried out according to Carciochi et al. [27]. Briefly, BSGs were subjected to mechanical agitation with a $w / v$ ratio of $1 / 30$, temperature of $80{ }^{\circ} \mathrm{C}, 72 / 28$ ethanol/water $(v / v)$, and an extraction time of $60 \mathrm{~min}$.

\subsection{Determination of Proanthocyanidins in Brewing Spent Grain Extracts by HPLC-FLD-MS Analysis}

The separation of proanthocyanidins was performed on an Agilent 1200 Series HPLC system (Agilent Technologies, Santa Clara, CA) equipped with a binary pump delivery system, a degasser, an autosampler, and FLD and MS detectors (MSD, model G1946A, Santa Clara, CA, USA). A Develosil Diol $100 \AA$ column $(250 \times 4.6 \mathrm{~mm}, 5 \mu \mathrm{m}$ particle size) purchased from Phenomenex (Torrance, CA, USA) was used for the analyses.

All solvents were HPLC-grade and were filtered in a filter disc of $0.45 \mu \mathrm{m}$. According to Robbins et al. [28], the elution binary gradient consisted of $\mathrm{CH} 3 \mathrm{CN} / \mathrm{HOAc}, 98 / 2(v / v)$ as solvent $\mathrm{A}$, and $\mathrm{CH}_{3} \mathrm{OH} / \mathrm{H}_{2} \mathrm{O} / \mathrm{HOAc} 95 / 3 / 2 v / v / v$ as solvent $\mathrm{B}$. The analyses started with $7 \%$ of phase $\mathrm{B}$ from 0 to $3 \mathrm{~min}$. Thus, solvent B was increased to $37.6 \%$ (from 3.1 to $57 \mathrm{~min}$ ) and then to $100 \% \mathrm{~B}$ over the next $3 \mathrm{~min}$ for $7 \mathrm{~min}$. After that, the initial condition was established, and they were maintained for $16 \mathrm{~min}$. The injection volume was $5 \mu \mathrm{L}$ and all the analyses were run at $35^{\circ} \mathrm{C}$. Additionally, fluorescence detection was conducted with an excitation wavelength of $230 \mathrm{~nm}$ and an emission wavelength of $321 \mathrm{~nm}$.

Moreover, identification of proanthocyanidins was carried out by HPLC-MS according to Verardo et al. [8]. Furthermore, quantification of PCs was done employing a calibration curve of (+)-catechin done from the limit of quantitation (LOQ) to $250 \mu \mathrm{g} / \mathrm{mL}$ (LOQ $=0.193 \mu \mathrm{g} / \mathrm{mL}$ ). In addition, the quantification of dimers, trimers, tetramers, pentamers, and the polymers was done using the correction factors suggested by Robbins et al. [28].

\section{Results and Discussion}

\subsection{Determination of Proanthocyanidin Compounds in Brewers' Spent Grains}

Table 1 shows the sum of the total content of proanthocyanidins according to the experimental design (Table 1). 
Table 1. Box-Behnken design (BBD) with the values of the sonotrode ultrasound (US) parameters with the experimental values for the dependent response of proanthocyanins (PCs) quantified by HPLC-fluorometric detector (FLD) in brewers' spent grain (BSG) extracts; d.w.—dry weight.

\begin{tabular}{ccccc}
\hline \multirow{2}{*}{ Experiment } & \multicolumn{3}{c}{ Independent Factors } & Dependent Factor \\
\cline { 2 - 5 } & $\mathbf{X}_{\mathbf{1}}$ & $\mathbf{X}_{\mathbf{2}}$ & $\mathbf{X}_{\mathbf{3}}$ & Total $\left(\boldsymbol{\mu g} \cdot \mathbf{g}^{-\mathbf{1}} \mathbf{d . w .}\right)$ \\
\hline 1 & 50 & 5 & 240 & 540.04 \\
\hline 2 & 100 & 5 & 240 & 548.25 \\
\hline 3 & 50 & 55 & 240 & 690.90 \\
\hline 4 & 100 & 55 & 240 & 802.25 \\
\hline 5 & 50 & 30 & 80 & 547.91 \\
\hline 6 & 100 & 30 & 80 & 849.32 \\
\hline 7 & 50 & 30 & 400 & 601.43 \\
\hline 8 & 100 & 30 & 400 & 792.07 \\
\hline 9 & 75 & 5 & 80 & 796.40 \\
\hline 10 & 75 & 55 & 80 & 977.69 \\
\hline 11 & 75 & 5 & 400 & 993.15 \\
\hline 12 & 75 & 55 & 400 & 1002.31 \\
\hline 13 & 75 & 30 & 240 & 832.04 \\
\hline 14 & 75 & 30 & 240 & 857.04 \\
\hline 15 & 75 & 30 & 240 & 752.68 \\
\hline
\end{tabular}

X1: acetone/water, X2: time, and X3: US power.

A total of 11 PCs were identified in BSGs according to their degree of polymerization and their mass spectra. As shown in Table 2 (and in Figure S1), the elution order depended on the number of flavan-3-ol units. Therefore, monomers eluted first and then the different oligomers eluted. In addition, for the same degree of polymerization, a higher degree of galloylation meant a higher retention time [8].

Table 2. Table of identification of proanthocyanidins from brewers' spent grain extracts by HPLC-MS; Rt-retention time.

\begin{tabular}{cccc}
\hline Peak & Rt (min) & Compound & {$[\mathbf{M}-\mathbf{H}]^{-}$} \\
\hline 1 & 6.7 & Catechin/epicatechin & 289 \\
2 & 17.6 & Procyanidin dimer & 577 \\
3 & 19.0 & Prodelphinidin dimer & 593 \\
4 & 21.2 & Prodelphinidin dimer II & 593 \\
5 & 24.4 & Procyanidin trimer & 865 \\
6 & 26.8 & Prodelphinidin trimer I (monogalloylated) & 881 \\
7 & 29.5 & Prodelphinidin trimer II (digalloylated) & 897 \\
8 & 32.8 & Procyanidin tetramer & 1153 \\
9 & 33.9 & Prodelphinidin tetramer (digalloylated) & 1457 \\
10 & 36 & Procyanidin pentamer & 1441 \\
11 & 51.7 & Polymers (degree of polymerization >5) \\
\hline
\end{tabular}

Moreover, quantification of PCs in brewing by-products was carried out using HPLC-FLD. The calibration curve of catechin was used to quantify the PCs. The correction factors were applied according to Robbins et al. [28]. The concentration values of PCs obtained in each experiment in the BBD are presented in Table 3. Briefly, the total content of PCs varied from $540.04 \mu \mathrm{g} \cdot \mathrm{g}^{-1} \mathrm{dry}$ weight (d.w.) to $1002.31 \mu \mathrm{g} \cdot \mathrm{g}^{-1} \mathrm{~d}$.w. Comparing the quantification of each compound, experiment 11, whose parameters of extraction were $75 \%$ acetone, $5 \mathrm{~min}$, and $400 \mathrm{~W}$ of US power, recovered higher amounts of catechin/epicatechin, dimers, trimers, and tetramers than the rest of the experiments. Finally, the major concentrations of procyanidin pentamer, the polymer, and the total content of PCs were obtained in experiment 12 with $75 \%$ acetone, $55 \mathrm{~min}$, and $400 \mathrm{~W}$ of US power. 
Table 3. Table of quantification of proanthocyanidins from brewers' spent grain extracts by HPLC-FLD expressed as $\mu \mathrm{g} \cdot \mathrm{g}^{-1} \mathrm{~d}$.w. UAE- $\mathrm{ultrasound-assisted} \mathrm{extraction;}$

LOQ-limit of quantitation.

\begin{tabular}{|c|c|c|c|c|c|c|c|c|c|c|c|c|c|c|c|}
\hline Proanthocyanidin Compounds & UAE 1 & UAE 2 & UAE 3 & UAE 4 & UAE 5 & UAE 6 & UAE 7 & UAE 8 & UAE 9 & UAE 10 & UAE 11 & UAE 12 & UAE 13 & UAE 14 & UAE 15 \\
\hline Catechin/epicatechin & 8.34 & 9.17 & 10.16 & 9.71 & 8.05 & 10.03 & 10.07 & 10.37 & 9.59 & 10.33 & 10.41 & 8.41 & 9.62 & 9.53 & 8.89 \\
\hline Procyanidin dimer & 50.08 & 70.49 & 52.50 & 85.90 & 40.06 & 73.45 & 44.02 & 82.34 & 57.47 & 76.36 & 100.92 & 64.17 & 98.56 & 88.97 & 73.94 \\
\hline Prodelphinidin dimer & 22.68 & 33.01 & 26.09 & 25.96 & 30.44 & 38.86 & 31.93 & 43.95 & 49.16 & 57.03 & 38.74 & 25.68 & 31.04 & 33.97 & 31.60 \\
\hline Prodelphinidin dimer II & 25.69 & 35.62 & 51.16 & 66.60 & 38.16 & 78.03 & 37.09 & 79.55 & 59.02 & 72.00 & 74.00 & 79.08 & 64.73 & 76.73 & 60.15 \\
\hline Procyanidin trimer & 73.11 & 28.69 & 61.50 & 54.93 & 54.45 & 67.35 & 37.20 & 64.29 & 88.65 & 92.85 & 103.78 & 52.06 & 103.23 & 97.27 & 95.05 \\
\hline Prodelphinidin trimer I (monogalloylated) & 35.58 & 73.86 & 56.78 & 97.85 & 49.08 & 101.98 & 45.60 & 95.27 & 92.53 & 122.39 & 121.94 & 81.68 & 98.98 & 107.81 & 83.69 \\
\hline Prodelphinidin trimer II (digalloylated) & $<$ LOQ & 48.58 & $<\mathrm{LOQ}$ & 82.52 & $<$ LOQ & 80.67 & $<\mathrm{LOQ}$ & 71.26 & 79.53 & 92.77 & 83.62 & 75.12 & 65.34 & 78.03 & 59.54 \\
\hline Procyanidin tetramer & $<\mathrm{LOQ}$ & 29.46 & $<\mathrm{LOQ}$ & 46.57 & $<\mathrm{LOQ}$ & 51.15 & $<\mathrm{LOQ}$ & 44.52 & 45.68 & 56.49 & 55.10 & 45.12 & $<\mathrm{LOQ}$ & $<\mathrm{LOQ}$ & $<\mathrm{LOQ}$ \\
\hline Prodelphinidin tetramer (digalloylated) & $<\mathrm{LOQ}$ & 32.70 & $<\mathrm{LOQ}$ & 52.06 & $<$ LOQ & 58.55 & $<\mathrm{LOQ}$ & 51.20 & 50.76 & 64.87 & 68.59 & 63.57 & $<$ LOQ & $<\mathrm{LOQ}$ & $<\mathrm{LOQ}$ \\
\hline Procyanidin pentamer & $<\mathrm{LOQ}$ & 17.64 & $<\mathrm{LOQ}$ & 26.50 & $<$ LOQ & 28.01 & $<\mathrm{LOQ}$ & 19.34 & 24.84 & 35.28 & 30.44 & 42.78 & $<\mathrm{LOQ}$ & $<\mathrm{LOQ}$ & $<\mathrm{LOQ}$ \\
\hline Polymers & 324.57 & 169.04 & 432.71 & 253.66 & 327.67 & 261.23 & 395.52 & 229.98 & 239.17 & 297.31 & 305.60 & 464.64 & 360.52 & 364.73 & 339.83 \\
\hline Total & 540.04 & 548.25 & 690.90 & 802.25 & 547.91 & 849.32 & 601.43 & 792.07 & 796.40 & 977.69 & 993.15 & 1002.31 & 832.04 & 857.04 & 752.68 \\
\hline
\end{tabular}


Proanthocyanidins were grouped as monomer, dimers, trimers, tetramers, pentamers, and polymers.

\subsection{Fitting the Model}

The regression model for the BBD was fitted employing the data from Table 1 in order to find the combined effect of extraction time, acetone/water ratio, and sonotrode US power on the response variable during the sonotrode US. For that, an analysis of variance (ANOVA) with 95\% confidence level was employed to analyze the regression model and to evaluate the effect of the coefficients for each factor (linear and quadratic terms) and the interaction between them (cross-product term). In fact, the evaluation of the model was carried out according to the significance of the regression coefficients which are displayed in Table 4. According to other works, the level of significance could be fixed at $\alpha<0.1$ in order to increase the number of significant terms [26]. In the present work, the model was analyzed at $\alpha<0.05$ and $\alpha<0.1$ The significant variables for the total content of PCs were the intercept $\left(X_{0}\right)(p=0.000426)$, the linear effect of acetone/water $\left(X_{1}\right)(p=0.058033)$ and its quadratic effect $\left(X_{11}\right)$ $(p=0.018319)$, the linear effect of time $\left(X_{2}\right)(p=0.060966)$, and the quadratic effect of the power $\left(X_{33}\right)$ $(p=0.085914)$. Furthermore, ANOVA revealed that the model presented a high correlation between the factors and the response variables with a coefficient of determination $\left(R^{2}\right)$ of 0.8999 (Table 4). In addition, the $p$-value of the regression model and the $p$-value of the lack-of-fit (LOF) were also used to verify the adequacy of the model. In fact, a high correlation term, a significant regression model $(p<0.05)$, and a non-significant LOF $(p>0.05)$ demonstrated the validity of the model (Table 4$)$.

Table 4. Regression coefficients and ANOVA table.

\begin{tabular}{cc}
\hline Regression Coefficients & Total Proanthocyanidins \\
\hline$\beta_{0}$ & $-1256.27^{*}$ \\
Linear & $53.07^{* *}$ \\
$\beta_{1}$ & $-1.19^{* *}$ \\
$\beta_{2}$ & -0.68 \\
$\beta_{3}$ & \\
Cross product & 0.04 \\
$\beta_{12}$ & -0.01 \\
$\beta_{13}$ & -0.01 \\
$\beta_{23}$ & \\
Quadratic & $-0.33 *$ \\
$\beta_{11}$ & 0.06 \\
$\beta_{22}$ & $0.00 * *$ \\
$\beta_{33}$ & 0.8999 \\
$R^{2}$ & 0.0074 \\
$p$ (regression model) & 0.3420 \\
\hline (lack-of-fit) &
\end{tabular}

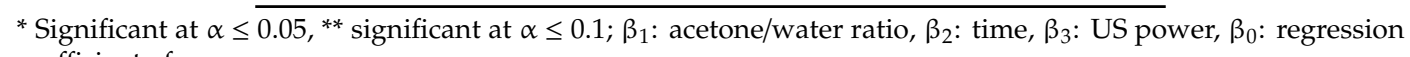
coefficient of mean.

\subsubsection{Analysis of Response Surfaces}

In order to determine the optimal value of each factor for the extraction of PCs from BSGs, response surfaces were plotted. Each pair of variables was depicted in three-dimensional surface plots, while the other factor was kept constant at a central level. Figure 1 shows the three-dimensional plots for the effects of acetone/water $(\%(v / v))(X 1)$ with time $(X 2)$, acetone/water $(\%(v / v))(X 1)$ with US power $(X 3)$, and time $(\mathrm{X} 2)$ with US power $(\mathrm{X} 3)$ on the concentration of the total content of PCs. 
A

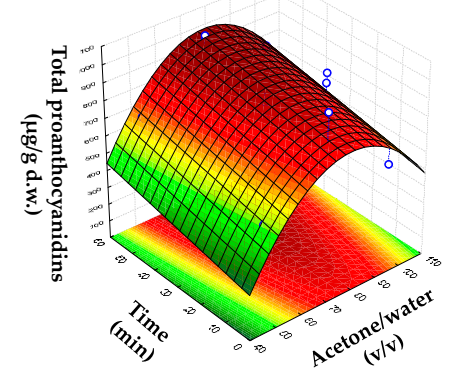

B

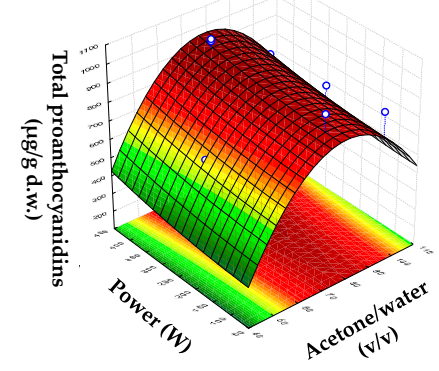

C

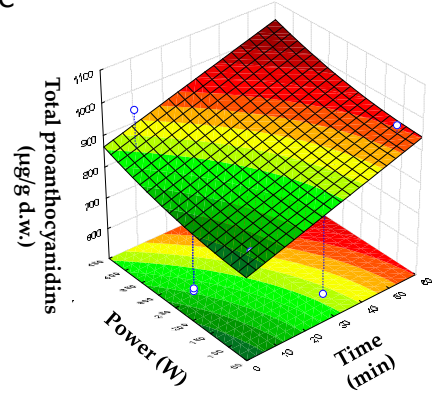

Figure 1. Response surface plots showing the combined effects of process variables for total proanthocyanidins: (A) acetone/water (\% $(v / v))$ vs. time ( $\mathrm{min}) ;(\mathbf{B})$ acetone/water $(\%(v / v))$ vs. ultrasound (US) power (W); (C) time (min) vs. US power (W).

In Figure $1 \mathrm{~A}, \mathrm{~B}$, it can be observed that the response of the total content of PCs increased when the concentration of acetone increased at first. After that, a decrease in response was observed when the maximum response was achieved. This shape was a consequence of the quadratic effect of acetone, which had a negative value, showing that an increase in this parameter more than a certain value tended to decrease the response. For example, Figure 1A shows an increase in total concentration of PCs if the content of acetone rose until the maximum value (75-85\%), for which the increase time caused a slight increase in the total concentration of PCs. Additionally, in Figure 1B, an increase in the content of total PCs up to 70-85\% acetone was observed where it started to reduce, whereas the response increased slightly at 70-85\% if the power increased. At last, Figure $1 \mathrm{C}$ shows the positive linear effect of time and power on the response; there was an increase in response with time and power.

\subsubsection{Optimization of Sonotrode US Parameters}

The optimal conditions were selected through the three-dimensional (3D) plots to obtain the highest content of PCs from BSGs, as shown in Table 5.

Table 5. Optimal conditions for sonotrode UAE.

\begin{tabular}{cc}
\hline Optimal Conditions & Sum of Proanthocyanidins $\left(\boldsymbol{\mu g} \cdot \mathbf{g}^{-\mathbf{1}} \mathbf{\text { d.w. }}\right)$ \\
\hline Acetone/ water ratio $(\%(v / v))$ & 80 \\
Time $(\mathrm{min})$ & 55 \\
US power & 400 \\
Predicted $\left(\mu \mathrm{g} \cdot \mathrm{g}^{-1}\right.$ d.w.) & $1012.7 \pm 15.1$ \\
Obtained value $\left(\mu \mathrm{g} \cdot \mathrm{g}^{-1}\right.$ d.w.) & $1023.0 \pm 8.9$ \\
Significant differences between predicted and obtained value & N.S. \\
\hline
\end{tabular}

N.S.: non-significant difference.

Briefly, optimal extraction conditions were $80 \%$ acetone/water $(v / v), 55 \mathrm{~min}$, and $400 \mathrm{~W}$ for US power. The final step of the RSM after selecting the optimal conditions was to verify the accuracy of the mathematical model. For that, an extraction at optimal conditions was done with the same methodology; the obtained value did not report significant differences with the predicted value.

According to the results, the maximum content of PCs was obtained at $80 \%$ acetone/water, because PCs with a high degree of polymerization were the most concentrated, and they were better extracted at a high percentage of acetone, since they were less polar than the other PCs, increasing their solubility in this solvent. Also, acetone was not an efficient solvent when used pure, showing good results when it was combined with water. This occurred due to increased solvation provided by the presence of water. Additionally, at a high time of extraction and maximum power, cell walls were disrupted, releasing proanthocyanidins from the cell constituents. The predicted values of the model were in accordance with the experimental data under the same conditions. In fact, no significant differences were noted between the two data. 


\subsection{Comparison between Conventional and Established Sonotrode Extraction}

Table 6 displays the comparison between the extraction of flavan-3-ols using sonotrode US at the optimal conditions established by our model and that using conventional extraction carried out according to Carciochi et al. [27].

Table 6. Comparison of proanthocyanidin content using sonotrode and conventional extractions ( $\mu \mathrm{g} / \mathrm{g}$ d.w.).

\begin{tabular}{ccc}
\hline Proanthocyanidin Compounds & Sonotrode Extraction & Conventional Extraction \\
\hline Catechin/epicatechin & $8.96 \pm 0.23$ & $3.89 \pm 0.36$ \\
Procyanidin dimer & $66.21 \pm 1.10$ & $21.34 \pm 1.04$ \\
Prodelphinidin dimer & $26.08 \pm 0.29$ & $10.25 \pm 0.92$ \\
Prodelphinidin dimer II & $80.43 \pm 1.62$ & $39.41 \pm 1.37$ \\
Procyanidin trimer & $53.19 \pm 1.06$ & $18.69 \pm 2.06$ \\
Prodelphinidin trimer I (monogalloylated) & $83.70 \pm 2.12$ & $42.16 \pm 1.89$ \\
Prodelphinidin trimer II (digalloylated) & $76.14 \pm 0.98$ & $35.47 \pm 1.25$ \\
Procyanidin tetramer & $47.09 \pm 0.63$ & $19.36 \pm 0.47$ \\
Prodelphinidin tetramer (digalloylated) & $65.22 \pm 1.52$ & $20.93 \pm 1.12$ \\
Procyanidin pentamer & $46.81 \pm 1.70$ & $18.71 \pm 0.43$ \\
Polymers & $469.21 \pm 6.69$ & $200.36 \pm 2.89$ \\
Total & $1023.04 \pm 8.9$ & $430.57 \pm 3.62$ \\
\hline
\end{tabular}

According to the results obtained, the proposed methodology recovered $57.9 \%$ more total content of PCs than conventional extraction. Therefore, sonotrode ultrasound-assisted extraction is a more effective technique than conventional extraction for the recovery of PCs from BSGs. These data are in agreement with the data presented by Carciochi et al. [27].

Moreover, comparison with the literature is difficult because the information about the proanthocyanidin composition of BSGs is scarce. Comparing the values of proanthocyanidins obtained in this work with that obtained in barley samples, the contents of catechin, procyanidins, and prodelphynidins obtained in this work were on the same order of magnitude as those obtained in barley samples [4,8]. According to Moreira and co-workers [29], the present data also confirmed that light malt types as used for pilsner beer production contain high amounts of phenolic compounds.

In spite of proanthocyanidins being degraded at high temperatures during malting, where barley is milled, mixed with water in the mash tun, and the temperature of mash slowly increased from 37 to $78^{\circ} \mathrm{C}$ to promote enzymatic hydrolysis of malt constituents [1], and during beer production, it was confirmed that a part of barley and hop proanthocyanidins still remain in the beer spent grains after beer production. Concentrations of catechin obtained at optimum sonotrode US conditions and in conventional extraction $\left(8.96 \pm 0.23\right.$ and $3.89 \pm 0.36 \mathrm{mg} \cdot \mathrm{g}^{-1} \mathrm{~d} . \mathrm{w} .$, respectively) were higher than that reported by Ikram et al. [30] in brewers spent grain samples (1.08 $\pm 0.04 \mu \mathrm{g} \cdot 100 \mathrm{~g}^{-1} \mathrm{~d}$.w.). These differences could be because the catechin content of BSG varies according to barley variety, harvest time, malting and mashing conditions, and the quality and type of adjuncts added in the brewing process [1], but could also be due to the extraction method adopted for the proanthocyanidin extraction.

\section{Conclusions}

HPLC-FLD-MS was used for the determination of proanthocyanidins in brewers spent grains for the first time. A Box-Behnken experimental design was used in order to optimize the sonotrode ultrasound-assisted extraction parameters to obtain the maximum proanthocyanidin content from BSG. According to the model, the most important effect on the response came from the quadratic term of acetone/water ratio, followed by the linear term of acetone/water, the linear term of the time of extraction, and the quadratic term of US power. The highest value of proanthocyanidins was obtained at $80 \%$ acetone/water $(v / v), 55 \mathrm{~min}$, and $400 \mathrm{~W}$. Finally, it was proven that sonotrode ultrasonic extraction is a more effective technique than conventional extraction method, providing a higher recovery of proanthocyanidins from BSG. 
To conclude, BSGs represent a good raw material that could be used for the extraction of bioactive compounds or could be reused for the production of functional flours. In this way, further work will be done in order to validate this hypothesis.

Supplementary Materials: The following are available online at http://www.mdpi.com/2076-3921/8/8/282/s1, Figure S1: Separation of BSG proantocyanidins by HPLC-FLD.

Author Contributions: Conceptualization, V.V. and A.M.G.; data curation, B.M.G. and E.D.C.; investigation, B.M.G., F.P., and U.T.; supervision, V.V., A.M.G., and M.F.C.; writing—original draft, B.M.G.; writing—review and editing, F.P., V.V., E.D., U.T., A.M.G., and M.F.C.

Funding: This project was supported by the University of Granada (project PPJI2017.16).

Acknowledgments: Vito Verardo thanks the Spanish Ministry of Economy and Competitiveness (MINECO) for the "Ramon y Cajal" contract (RYC-2015-18795). Beatriz Martín García would like to thank the University of Granada for the "convocatoria de movilidad internacional de estudiantes de doctorado" grant.

Conflicts of Interest: The authors declare no conflicts of interest. The funders had no role in the design of the study; in the collection, analyses, or interpretation of data; in the writing of the manuscript, or in the decision to publish the results.

\section{References}

1. Gupta, M.; Abu-Ghannam, N.; Gallaghar, E. Barley for brewing: characteristic changes during malting, brewing and applications of its by-products. Compr. Rev. Food Sci. Food Saf. 2010, 9, 318-328. [CrossRef]

2. Hajji, T.; Mansouri, S.; Vecino-Bello, X.; Cruz-Freire, J.M.; Rezgui, S.; Ferchichi, A. Identification and characterization of phenolic compounds extracted from barley husks by LC-MS and antioxidant activity in vitro. J. Cereal Sci. 2018, 81, 83-90. [CrossRef]

3. Sharma, P.; Longvah, T. Chapter 2: Barley. In Whole Grains: Processing, Product Development and Nutritional Aspects; Mir, S.A., Manickavasagan, A., Shah, M.A., Eds.; CRC Press: Boca Raton, FL, USA, 2019; pp. $25-49$.

4. Madigan, D.; McMurrough, I.; Smyth, M.R. Determination of proanthocyanidins and catechins in beer and barley by high-performance liquid chromatography with dual-electrode electrochemical detection. The Anal. 1994, 119, 863-868. [CrossRef]

5. Gómez-Caravaca, A.M.; Verardo, V.; Berardinelli, A.; Marconi, E.; Caboni, M.F. A chemometric approach to determine the phenolic compounds in different barley samples by two different stationary phases: A comparison between C18 and pentafluorophenyl core shell columns. J. Chromatogr. A 2014, 1355, 134-142. [CrossRef] [PubMed]

6. Gu, L.; Kelm, M.A.; Hammerstone, J.F.; Beecher, G.; Holden, J.; Haytowitz, D.; Gebhardt, S.; Prior, R.L. Concentrations of proanthocyanidins in common foods and estimations of normal consumption. J. Nutr. 2004, 134, 613-617. [CrossRef] [PubMed]

7. Holtekjolen, A.K.; Kinitz, C.; Knutsen, S.H. Flavanol and bound phenolic acid contents in different barley varieties. J. Agric. Food Chem. 2006, 54, 2253-2260. [CrossRef] [PubMed]

8. Verardo, V.; Cevoli, C.; Pasini, F.; Gómez-Caravaca, A.M.; Marconi, E.; Fabbri, A.; Caboni, M.F. Analysis of oligomer proanthocyanidins in different barley genotypes using high-performance liquid chromatography fluorescence detection - mass spectrometry and near-infrared methodologies. J. Agric. Food Chem. 2015, 63, 4130-4137. [CrossRef] [PubMed]

9. Verardo, V.; Gómez-Caravaca, A.M.; Marconi, E.; Caboni, M.F. Air classification of barley flours to produce phenolic enriched ingredients: Comparative study among MEKC-UV, RP-HPLC-DAD-MS and spectrophotometric determinations. LWT-Food Sci. Technol. 2011, 44, 1555-1561. [CrossRef]

10. Li, H.J.; Deinzer, M.L. Proanthocyanidins in Hops. In Beer in Health and Disease Prevention; Preedy, V.R., Ed.; Accademic Press: Orlando, FL, USA, 2009; pp. 333-348.

11. Yamamoto, H.; Nagano, C.; Takeuchi, F.; Shibata, J.; Tagashira, M.; Ohtake, Y. Extraction of polyphenols in hop bract part discharged from beer breweries. J. Chem. Eng. Jpn. 2006, 39, 956-962. [CrossRef]

12. Mayer, R.; Stecher, G.; Wuerzner, R.; Silva, R.C.; Sultana, T.; Trojer, L.; Feuerstein, I.; Krieg, C.; Abel, G.; Popp, M.; et al. Proanthocyanidins: Target compounds as antibacterial agents. J. Agric. Food Chem. 2008, 56, 6959-6966. [CrossRef] [PubMed]

13. Xu, X.; Xie, H.; Wang, Y.; Wei, X. A-Type proanthocyanidins from lychee seeds and their antioxidant and antiviral activities. J. Agric. Food Chem. 2010, 58, 11667-11672. [CrossRef] [PubMed] 
14. Nandakumar, V.; Singh, T.; Katiyar, S.K. Multi-targeted prevention and therapy of cancer by proanthocyanidins. Cancer Lett. 2008, 269, 378-387. [CrossRef] [PubMed]

15. Tatsuno, T.; Jinno, M.; Arima, Y.; Kawabata, T.; Hasegawa, T.; Yahagi, N.; Takano, F.; Ohta, T. Anti-inflammatory and anti-melanogenic proanthocyanidin oligomers from peanut skin. Biol. Pharm. Bull. 2012, 35, 909-916. [CrossRef] [PubMed]

16. Martín-Fernández, B.; de las Heras, N.; Valero-Muñoz, M.; Ballesteros, S.; Yao, Y.Z.; Stanton, P.G.; Fuller, P.J.; Lahera, V. Beneficial effects of proanthocyanidins in the cardiac alterations induced by aldosterone in rat heart through mineralocorticoid receptor blockade. PLoS ONE 2014, 9, 1-10. [CrossRef] [PubMed]

17. Yang, L.; Xian, D.; Xiong, X.; Lai, R.; Song, J.; Zhong, J. Proanthocyanidins against oxidative stress: From molecular mechanisms to clinical applications. Biomed Res. Int. 2018, 8584136. [CrossRef] [PubMed]

18. Zuorro, A.; Iannone, A.; Lavecchia, R. Water-organic solvent extraction of phenolic antioxidants from brewers' spent grain. Processes 2019, 7, 126. [CrossRef]

19. Meneses, N.M.G.; Martins, S.; Teixeira, J.A.; Mussatto, S.I. Influence of extraction solvents on the recovery of antioxidant phenolic compounds from brewer's spent grains. Sep. Purif. Technol. 2013, 108, 152-158. [CrossRef]

20. Heng, M.Y.; Tan, S.W.; Yong, J.W.H.; Ong, E.S. Trends in analytical chemistry emerging green technologies for the chemical standardization of botanicals and herbal preparations. Trends Analyt. Chem. 2013, 50, 1-10. [CrossRef]

21. Galanakis, C.M. Recovery of high added value component from food wastes: Conventional, emerging technologies and commercialized applications. Trend Food Sci. Tech. 2012, 26, 68-87. [CrossRef]

22. Gu, L.; Kelm, M.A.; Hammerstone, J.F.; Beecher, G.; Holden, J.; Haytowitz, D.; Prior, R.L. Screening of foods containing proanthocyanidins and their structural characterization using LC-MS/MS and thiolytic degradation. J. Agric. Food Chem. 2003, 51, 7513-7521. [CrossRef]

23. Hellström, J.K.; Törrönen, A.R.; Mattila, P.H. proanthocyanidins in common food products of plant origin. J. Agric. Food Chem. 2009, 57, 7899-7906. [CrossRef] [PubMed]

24. Monagas, M.; Quintanilla-López, J.E.; Gómez-Cordovés, C.; Bartolomé, B.; Lebrón-Aguilar, R. MALDI-TOF MS analysis of plant proanthocyanidins. J. Pharm. Biomed. Anal. 2010, 51, 358-372. [CrossRef] [PubMed]

25. Tao, Y.; Sun, D.W. Critical reviews in food science and nutrition enhancement of food processes by ultrasound: A review. Crit. Rev. Food Sci. Nutr. 2015, 55, 570-594. [CrossRef] [PubMed]

26. Díaz-de-Cerio, E.; Tylewicz, U.; Verardo, V.; Fernández-Gutiérrez, A.; Segura-Carretero, A.; Romani, S. Design of sonotrode ultrasound-assisted extraction of phenolic compounds from Psidium guajava L. leaves. Food Anal. Met. 2017, 10, 2781-2791. [CrossRef]

27. Carciochi, R.A.; Sologubik, C.A.; Fernández, M.B.; Manrique, G.D.; D’Alessandro, L.G. Extraction of antioxidant phenolic compounds from brewer's spent grain: Optimization and kinetics modeling. Antioxidants 2018, 7, 45. [CrossRef] [PubMed]

28. Robbins, R.J.; Leonczak, J.; Johnson, J.C.; Li, J.; Kwik-Uribe, C.; Prior, R.L.; Gu, L. Method performance and multi-laboratory assessment of a normal phase high pressure liquid chromatography-fluorescence detection method for the quantitation of flavanols and procyanidins in cocoa and chocolate containing samples. J. Chromatogr. A 2009, 1216, 4831-4840. [CrossRef] [PubMed]

29. Moreira, M.M.; Morais, S.; Carvalho, D.O.; Barros, A.A.; Delerue-Matos, C.; Guido, L.F. Brewer's spent grain from different types of malt: Evaluation of the antioxidant activity and identification of the major phenolic compounds. Food Res. Int. 2013, 54, 382-388. [CrossRef]

30. Ikram, S.; Huang, L.; Zhang, H.; Wang, J.; Yin, M. Composition and nutrient value proposition of brewers spent grain. J. Food Sci. 2017, 82, 2232-2242. [CrossRef]

(C) 2019 by the authors. Licensee MDPI, Basel, Switzerland. This article is an open access article distributed under the terms and conditions of the Creative Commons Attribution (CC BY) license (http://creativecommons.org/licenses/by/4.0/). 